3

LINGUACULTURE

\title{
LIKE DEATH BUT WITHOUT DEATH: THE LANGUAGE-DEATH-METAPHOR AND ANOTHER OPTION
}

\author{
Jonathan Blake FOSTAR \\ Illinois State University, U.S.A.
}

\begin{abstract}
'Death', 'dying', 'dead', 'extinct', 'endangered', 'murdered', 'resurrected' etc. The language-death-metaphor for language loss has permeated the contemporary linguistic literature for decades and decades. While biological metaphors for language have served a function historically in the study of language endangerment, this paper aims to outline how the language-death-metaphor specifically fails in that functioning. Maybe, the metaphor does not actually articulate what we are trying to articulate about a process common to all languages. This paper will dissect 'language death' cross-linguistically, investigating the changes in morphology, the loss of domains, creolization, and language shift that are all often purported to be 'symptomatic' of a language in its 'last days'. I will then propose an alternative term, 'phasing', that might more clearly describe the process by which a language becomes more or less dynamic, more or less adaptable, more or less use(ful)d over time. The more accurate the terminology, the more specific the tool, the more that might be done to assist from the periphery in language reclamation efforts, to aid in slowing or reversing the process of linguistic loss, and to support the speakers of 'dying' languages more productively in their already ongoing effort(s).
\end{abstract}

Keywords: linguistics, language death, language obsolescence, language revitalization, metaphor.

\section{INTRODUCTION}

As of the early part of this century, "the world's 6.34 billion people [spoke] 6,912 languages” (Harrison 13). Approximately 7,000 languages are a fraction

LINGUACULTURE vol. 12, no. 2, 2021

Published: 31 December 2021

DOI: 10.4773/lincu-2021-2-0200

ISSN (print): 2067-9696 || ISSN (online): 2285-9403 || www.journal.linguaculture.ro 
of the linguistic diversity documented only half a century earlier; there has been a $40 \%$ decline in the number of total global languages since the 1950s (Whalen and Simons 169). The world's remaining languages are not distributed evenly and tend to follow "the distribution of indigenous peoples across the globe... where populations are small and sparsely distributed" (Harrison 11). Regions with great linguistic diversity tend to have the smallest populations of speakers. The linguistic power balance too reflects the geopolitical landscape and even the distribution of global wealth. If we look at only "the top 10 biggest languages," we can account for the spoken languages of "just over 50 percent of humans" (Harrison 13). On the other hand, "the smallest half of the world's languages...are spoken by a mere 0.2 percent of the global population" (Harrison 13).

The sharp reduction in linguistic diversity is a direct consequence of language 'death'. Now, a whole menagerie of terms gets thrown around to describe this loss of languages: 'death', 'dying', 'dead', 'extinct', 'extinction', 'endangered', 'endangerment', 'obsolescent', 'moribund', and so on. 'Death' seems to be for all intents and purposes a sort of industry standard, and hopefully in the next couple of pages, I will explain why this is poor selection of metaphor. For clarity's sake, for now, I will stick with 'language death', which can (temporarily) be defined as a language which "(1) has no native speakers, (2) is not used in everyday communication by a speech community, and (3) does not undergo normal processes of change” (Amery 21).

\subsection{Latin}

Latin, the most famous of 'dead' languages, oddly enough never seems to have 'died'. The Vatican is adding new words all the time, like 'autobirota' for 'motorcycle'. Latin, albeit in many ways reduced, has for the most part carried on without significant interruption for a very long time. What then are we even saying when we say Latin 'died'? It is clear at least that effectively "the repertoire of registers [suffered] attrition from the bottom up, being abandoned first in the family vernacular and surviving ultimately only in the most elevated contexts" (Hill 260). Latin's use, over time, for certain, reduced. At the same time, the language, dispersed via centuries of Roman expansion, stretched out over an enormous geographical area of linguistic coverage; the language needed to fill multiple geopolitical roles. Latin was needed to fulfil wildly divergent needs for wildly divergent peoples, and thereby could not stay static or stable (Amery). In many ways, "spoken Latin did not die;" instead, it evolved in multiple places at multiple times "into what we now recognize as different languages” (Heller 249). Latin, though synonymous with 'dead' language in a 
lot of ways, "survived in the form of the Romance languages", and of course in the contemporary version of Latin itself (Heller 248).

Although the romance languages are mutually unintelligible and thereby classified differently from Latin and from each other, Latin itself as a contiguous object was never really a unified whole in the first place. The Latin of "the common people" diverged from the Latin of Cicero, and even that was "not uniform" with "many variations...according to the local background of the speakers” (Heller 249). More so than an 'alive' : 'dead' binary, there seems to be a spectrum of Latins, interacting and negotiating with other local languages and each other. These changes took long periods of time and make it difficult to point to a moment where Latin could be said to have 'died'. The reality is that Latin has never ceased to be a spoken language; it has always had a robust existence in written text. Latin did not 'die', it shattered, and some pieces carried on, business as usual.

\section{2. 'DYING'}

But all 'dying' languages do not follow the Latinate pattern; not only are there plenty of ways to die, but there is variety in kinds of 'dying'. It may be worth constructing a quick typology of language 'death' to try and pin down the term to something more specifically linguistic. As other typologies of language ‘death' make clear, “no...framework exists...even the subject as a whole has no agreed name. Terms such as obsolescent, moribund, and endangered are employed in a variety of senses...lacking in generality" (Crystal 93). We can, however, at least identify general, directional trends, patterns for 'dying', often identifiable only once a language has already 'died'.

The quickest type of language loss is often referred to as a 'sudden' or 'radical death' found in cases like Tasmania (Campbell and Muntzel). This type of obsolescence is "virtually a biological death" and generally accompanies "population collapse and cultural destruction” (Hill 260). 'Radical death' does not necessarily require genocide; "severe political repression" is significant enough to cause "speakers [to] stop speaking the language out of self-defense" (Campbell and Muntzel 83).

A slower type of language loss can be referred to then as "gradual death" or "the loss of a language due to...[a] shift to the dominant language in language-contact situations" (Campbell and Muntzel 184-5). This, more common, slow movement towards another language usually occurs over multiple generations and does not affect all speakers at the same time or in all the same social areas of language use (Hill). Like 'language shift', 'gradual death' is a kind of sociolinguistic movement of a group from one language-space to another. It is in these protracted cases that perhaps direct evidence of what 
'dying' looks like presents itself. And the most visible place to look for these traces probably sits somewhere within the morphology.

\section{MORPHOLOGY}

The question of morphology is effectively asking if there might be a relationship "between persistence of form and persistence of use" (Woolard 355). The morphemes do not just change of their own accord. There is "a tendency for marked forms to be replaced by less marked ones" (Campbell and Muntzel 187). Or perhaps "marked forms may be used excessively" (Campbell and Muntzel 188). Can we expect "impoverishment" and "structural simplification" from local languages under the influence of an incoming, dominating language (UNESCO)? Does language 'death', actually, "differ much from change in general"; does it happen "more rapidly" (Hoenigswald 349)? Can we make a single morphological prediction when we consider the 'death' of a language?

The answer is maybe and also maybe not. Often "dying languages characteristically show reduction of one kind or another - or, most often, of many kinds at once" (Dorian 590). Let me briefly narrow in on East Sutherland Gaelic to make a case as to whether this reduction via 'death' or 'dying' is distinguishable from "'classical' pidginization" or other kinds of language change (Dorian 590), since often "complex sentence phenomena [are] also [also] reported as absent in pidgin languages" (Hill 149). Perhaps they then are similar processes, or even the same but inverted, like maybe "language death might resemble the process of creolization of pidgins, but in reverse” (Hill 259).

\subsection{East Sutherland Gaelic}

As of 1978, East Sutherland Gaelic was "spoken by fewer than 150 people, all of them bilingual in English" in northern Scotland (Dorian 592). For my current purposes, this old data should work just fine; the current status of ESG in terms of viability is not as important as whether or not the changes while it is/was 'dying' could be theorized in some more specific sort of way. This paper samples cross-linguistically and cross-temporally for this reason.

As ESG was being pushed out by English, one of the productive morphological markers to look at was the formation of noun plurals, or more specifically, suffixation, watching for any incoming morphemes replacing the standards one would expect native speakers to produce when elicited. The results of a study eliciting responses from native speakers demonstrated that amongst plural formations (of so called semi-speakers, but more on this later) in ESG, two actually showed measurable decline: "vowel alternation combined 
with final mutation... and the lengthening of the final consonant” (Dorian 597). Although the decline was relatively small, at approximately 10\% (compared to fluent speakers, or the 'standard'), since both are distinctly "Celtic morphological device[s]" it is at least still some direct evidence of 'dying', morphologically (Dorian 597). Speakers with the weakest fluency showed the most change, as expected. But actual, direct evidence of English influence was small, mostly in the appearance of "a few /-(on)s/ noun plurals (1.5\% [of total plural utterances])" not found in 'standard' ESG itself (Dorian 607). In all actuality, it seems that ESG is 'dying' as ESG, not a 'sicklier' version; rather than undergoing dramatic reductions and change within the morphology, ESG is primarily (almost exclusively) undergoing reduction in domains of use, or in other words, "ESG might be said to be dying... with its morphological boots on" (Dorian 608).

\section{DOMAIN}

As ESG demonstrates, language 'death' is not really 'diagnosed' through these internal 'symptoms' of the morphology; it is not always linguistic, strictly speaking, but can instead be seen by considering "reductions in the range of functional contexts in which a language can be used" (Hill 269). These social contexts can also be referred to as domains (Fernando et al.). Now to be clear, the 'dying' language does not leave a vacuum in various social domains as its frequency of use reduces; it is always replaced by something. But even when we can demonstrate that a language is atrophying with regards to communal usage, "it may be difficult to distinguish some changes due to the language death process from the consequences of other kinds of language contact" (Campbell and Muntzel 195).

It is a matter of degrees, degrees in terms of the loss of speakers themselves, degrees in terms of the extent of the change in the language, degrees to which the speakers actively participate in the changing of domains of use. Overall reduction is "the cumulative outcome of individual practices" culminating in larger communal patterns (Mufwene 218). Sometimes, speakers seem perfectly "content to let [their language] die" (Whalen and Simons 170). More often, they are adapting to changing local political dynamics, adopting the incoming majority language "so that their children will have better job prospects or because...[it] is simply not promoted...[or] for fear of persecution" (Fernando et al. 48). To go even further, in certain cultural contexts, language might not be "as important a potential symbol of ethnic identity as some are led to believe...[it] is not an immutable part of group identity" (Dimmendaal 28-9). To take a look at some of this domain reduction, one potential place to turn to is the Uto-Aztecan language family. 


\subsection{Uto-Aztecan}

Uto-Aztecan is a family of more than thirty languages spoken by indigenous peoples of the far-western regions of both the United States and Mexico. Many of these languages are still thriving today with large speaker populations, but others faired worse, particularly in California which experienced the worst literal genocide within this group of indigenous peoples (Hill). However, with some exceptions, "language death in North America has generally been taken to be the result of language shift, rather than the result of the death of speakers" (Hill 261). This is not to say that American settlers did not try. It just seems to be the case that with many Uto-Aztecan languages, "even with population reduction ... [they] have proved to be surprisingly resistant to language loss" (Hill 262). In a way, the languages manage to, somehow persist, to linger, to carry-on.

But it is true that many Uto-Aztecan languages, especially languages often reserved for very specific domains, have completely vanished. Since the middle of the $20^{\text {th }}$ century, "no speaker found... has been able to use any of the 'high languages' used in oration and oral history," but two types of "linguistic routines" seemed to remain; that of "performing the 'remembering' of a few words, and the sly mention of obscenities" (Hill 264). As the languages lose their 'high' domains, they continue to persist, in some form, in 'low' ones. Maybe this is the model for 'dying'.

\subsection{Sirenikski}

While this seems to be a pattern, that of a sort of top-down loss, across languages of the region, "there is not enough homogeneity in the process to justify... universals" (Hill 272). Something very different happened in the case of Sirenikski, for example, which went quickly 'extinct' in the early 1900s (Krupnik). Rather than replaced by the dominant language of the colonial power, Sirenikski was 'killed' by the larger, indigenous language in the region. Sirenikski was never used for inter-tribal communication; it, in some sense, thrived while the group remained isolated. But as the incoming European power(s) began to displace native peoples, these groups were pushed into adopting one language or another in order to communicate across various ethnosocial domains. Diverse groups of indigenous people now needed collaboration to survive colonization. As intertribal cooperation increased, languages previously non-competitive were suddenly thrust into competition. Sirenikski did not win this contest; its "rapid extinction...can be explained as the decline of the previous tribal seclusion, the strengthening of Eskimo inter-tribal 
contacts and communications" (Krupnik 15). In order for previously separated peoples to establish a new, more "coherent social entity, [it] requires [both] social and linguistic integration” (Krupnik 16). Sirenikski 'dies' as a new social group is 'born'.

These internal changes that seem to accompany the 'death' are motivated by external force(s) generally. There does not seem to be a change to a particular domain or set of domains that predetermines the 'lifespan' of a language. This is not a $16^{\text {th }}$ or $18^{\text {th }}$ or $21^{\text {st }}$ century issue; languages have been 'dying' for forever. They have "been going extinct as the consequence of environmental catastrophes...intervention of new tools or weapons...agriculture, population movement...or religious or secular imperialism” (Fernando et al. 48). The rate seems to have increased through globalization, but it has also been proposed that this could also be a matter of visibility (Fernando et al. 48).

Even though 'dying' seems to be in many ways unquantifiable, the practical reality is that it is, to some extent, a numbers game. Geopolitical expansion and exploitation at the hands of a subset of European states "enormously increased the number of people who speak certain languages and decreased the number of languages that were spoken" (Karttunen and Crosby 161). Sometimes, as in the Tasmanian case, the loss of an indigenous language is genocidal, a colonial power literally murders every speaker, destroys a culture, erases a language from the world. And although this general power dynamic is pervasive across the colonial world, the majority of recent language 'deaths' "did not involve extinction of the people who once spoke them...[they] disappeared [often] because colonizers...did not learn them and held them in contempt” (Karttunen and Crosby 161). This external pressure becomes internalized within a community; there are some clear, material benefits for speakers to adopt the language of the colonizer, "which forces the community to give up its language" (Sasse 9-10). The material-linguistic value of the colonizing language "is enormously inflated" by the socioeconomic power of the colonizer(s), "while that of local languages is flattened" (McCarty 147). While this power relation "does not uniformly affect the whole world," it does mark a type or pattern that perhaps has something to say about language 'death' broadly (Mufwene 208-9).

\subsection{Tasmanian}

There are many tragic examples in which this exact pattern has played out with violence and horror. This cannot be clearer than in Tasmania, where the language and its speakers were killed, very literally, a place where horrific words like 'exterminated' come to mind. After contact, "Tasmanians were shot where they were found, or rounded up into prison camps...the last of them, a 
woman called Trucanini...[was] raped by the white convicts and then used by the authorities as a pawn to bring her people in, died in 1876" (Collins 247). Tasmanian was 'dead' along with every Tasmanian.

\subsection{Bandanese}

In Indonesia, a similar situation happened with Banda in 1621 after the arrival of the Dutch East India Company. Prior to contact, the population "was 15,000, but less than 1,000 after" (Collins 249). The Bandanese "themselves survived the murders and displacement of the seventeenth century...they cautiously and secretly regrouped" allowing their language, after undergoing serious transformation, to 'survive', in "socially complex and layered” ways (Collins 249).

It would be inaccurate to say that 'killing' the Bandanese language was the goal of the Dutch. Their "aim was simply the securing of a commodity (nutmeg) monopoly by murdering and enslaving the indigenous producers...language death did not enter into the calculations" (Collins 251). The decision by the colonizers to 'depopulate' the islands was ethno-economic, not linguistic, and the restructuring and resettling of the local communities being 'depopulated' concluded with the attrition and loss of indigenous languages. The "collateral damage" resulting from the death of the Bandanese people(s) was the ‘death' of the Bandanese language(s) (Collins).

\section{SEMI-SPEAKERS}

The problem with measuring language 'death' by counting speakers is "who exactly counts as a 'real speaker' of an endangered language” (Boltokova 13). As a speaker community gets smaller, it can become difficult to establish linguistic competency; speakers themselves are divided in terms of who really speaks a given language. 'Semi-speakers', or speakers capable "of 'getting by' but who are not fluent enough to be counted by either language activists or local community members" (Boltokova 13) becomes a kind of catch-all term "covering anyone and everyone who is not completely fluent in a language" (Boltokova 23). However, no one seems to have a universal definition for 'fluent', leaving fluency situational.

This has not stopped some thinkers from identifying semi-speakers, poorly defined or not, as "the locus of language decay...[the] 'forgetters"” (Sasse 58). While this may sometimes be the case for reasons of frequency and need among semi-speakers, it reduces the vital role of partial users of a given language to something aberrant or even destructive. In fact, speakers have a 
wide range of competency, a gradient. The prospect is not either/or. Semispeakers are the location of change; the changes they are making to the language are the language. Innovation is essential to linguistic survival, and two speakers never speak exactly the same. All speakers are, in a sense, semi-speakers. And at present these novel innovators of a language "are being called on to fulfil a leadership role in the community" as a group loses 'real' speakers (Counceller 17). Semi-speakers are the stewards of the future, as the previous custodians disappear. All semi-speakers are speakers.

\section{LANGUAGE REVITALIZATION}

If languages can change in one direction, reduction, it follows that they can also change in the opposite. A language should be able to gain areas of use, gain a morpheme, or a lexical item, or, perhaps, even a grammar. Language change in this direction is often called revitalization, and is, though not necessarily always, intentional on the part of a community of speakers. Language shift can but "does not necessarily result in language obsolescence" as often the processes can be altered or influenced (Brenzinger and Dimmendaal 3).

It is worth pointing out that a lot of this work, the work of reversing or even preventing language loss, has been ongoing in the communities the languages belong to, long before universities showed any interest, both in formal (community programs, ritual, ceremony, politic, etc.) and informal (partial use(s) in the home, cultural traditions, etc.) ways (Counceller). Any support or intervention on the part of contemporary scholars must be at the behest and instruction of the language community, as we are very late to the conversation.

There actually is not as much by way of a deluge of contemporary scholarship on revitalization possibilities and projects. Partly, this is due to the assumption that these efforts often "have been devoted largely to developing writing systems" which is often mocked as "preservation" rather than a legitimate agentive effort of a community to make its own language choices (Mufwene 208). The problem with this dismissiveness is that (1) current revitalization efforts go far further than a system for writing; and (2) a writing system can be a(n essential) partial component of a language. Without getting too ontological, a language $\neq$ its speakers. It cannot only consist of a long series of replaceable speakers and remain a contiguous object at the same time; we can talk about 'Latin', the same 'Latin', as existing before, during, and after the life of any of its speakers (think of the Argonaut). The de-deification of written text was an important step in the history of linguistics, but the total dismissal of written text as being a possible container of a language, of linguistic information, of data, is silly, and more seriously, absolutely contributes to the 
dismissal of efforts on the part of indigenous communities to take full ownership of their language and assert linguistic rights historically denied.

Like 'death', there are multiple types of revitalization also, in a sort of discordant parallel; "language revitalization [can be used to describe] revival efforts where some fluent speakers of the language remain" (Amery 20). When speakers no longer remain, there are still a number of adjacent possibilities, dependent on alternative resources. When there are "no fluent speakers, but...a significant amount of the language is [still] known within the community," we can designate revival efforts as "language renewal" (Amery 20). These efforts, without active living speakers, still usually depend on the spoken, oral tradition within the community, more so than historical or external records.

\section{LANGUAGE RECLAMATION}

There is a type of revival of a language even further removed, supposedly 'lost', that is also a real possibility: language reclamation. Reclamation can be more narrowly defined as "revival in situations where the language is no longer spoken and little is known orally...to relearn a language from material recorded... when the language was spoken” (Amery 19). For this approach to be possible, it requires both a reconfiguration of what we think counts as a language, and "a range of linguistic techniques to retrieve, piece together, develop and transform the language into a form capable of being relearned and used for a range of contemporary purposes” (Amery 20). This is the process of making the language more dynamic.

This approach still "requires minimally a sketch grammar and a reasonable vocabulary, or at least records of a number of genetically related languages which can be used to generate" a new vocabulary (Amery 25). And this need is not without its problems, as many of the worlds 'dead' languages have only wordlists remaining. I could speculate on a few possibilities, mostly involving grafting these wordlists onto a grammar of another, related language, but obviously with any reconstruction work, ultimately any program will be highly situational, and must be at the behest of the community of speakers.

Our primary concern here, the language-death-metaphor, rules out reclamation as a possibility, as a biological entity does not resurrect. The 'revived' language cannot even be considered the same as the original language, for any discontinuity in speakers, must result in a discontinuity of the language (Amery). This is where the metaphor springs its trap. A language is in the hands of its speakers, not the hands of linguists, so it is worth considering two cases of language revival from the point of view of the owners of the language, its speakers. As even UNESCO states, "in the end, it is the speakers, not outsiders, 
who maintain or abandon languages.” Does it not follow that we should extend that logical conclusion to the languages already considered 'abandoned' also?

\subsection{Hebrew}

The most studied case, in many minds the only case, of language revival is that of modern Hebrew. But how did Hebrew shift from a 'dead' language to a 'living' one that is not only widely spoken but has adapted itself to operate in all new domains of its speakers? The answer is not particularly complex: it was never 'dead'. The language "never died," it continued visibly as the textual language of a widespread religious tradition, and more so, "remained the cultural language of" the Jewish diaspora (Bar-Asher 29). Hebrew remained the language of both aging religious texts and new creative works from the dispersed Jewish communities.

In effect, the 'resurrection' of Hebrew "was more a matter of actualizing the existing potential” (Bar-Asher 30). A basic set of traces, records, in concert with innovative approaches to grafting material from new sources to update Hebrew's capacity for operating in new and changing domains of use, allowed for Hebrew's revitalization as a robust and dynamic linguistic system. Numerous possible milestones exist in the history of Hebrew's revitalization, but "essentially...the rebirth of Hebrew was effected at and around each of [them]...the sum ...reveals the total picture" (Bar-Asher 28). This, in fact, is the model for the reclamation of all languages. It is not so much a 'resuscitation,' rather the remaining material containing traces of a given language is used collaboratively with new grammars and lexical items from related languages and community-driven intentional, proscribed changes, to reinvigorate what is in fact already present.

\subsection{Kaurna}

By contrast, a smaller, local language like Kaurna does not have a long history of concentrated efforts to revitalize the language. Besides the difference in sizes of the two speaker communities, Kaurna also was subject to a different set of external forces than Hebrew, creating a very different base of remaining linguistic material to work with. Kaurna did not change so much as it was replaced, like "many indigenous languages in Australia" which "'died' because all their speakers have died [/been killed], or because all the speakers have adopted other languages" (Amery 21). Kaurna has no remaining speakers, nor "sound recordings...archival film, wax cylinder recordings, reel to reel tapes or...digital sound recordings" (Amery 32). 
The goal is not to uncover additional resources to work with, as in more traditional archaeology, but rather the "task is to transform Kaurna from an historical relic...into a dynamic 'living' entity” (Amery 27). This requires Kaurna's future speakers making significant transformations to Kaurna rather than relying on the (missing) historical records. It "entails restoring the functional links and support mechanisms that sustain the language...both a linguistic and social process" (Amery 7). But reclaimers are not without any lessons, schematics or models, there are strategies, often the failed ones, available to learn from. For example, in the process of Hebrew revitalization, "some of the earliest new terms introduced were long, cumbersome and unwieldy periphrastic constructions" (Amery 38). Kaurna's indigenous reclaimers will need to invent new lexical and grammatical items but can do so with a new sort of efficiency as we continue to learn which linguistics choices appear to work and which work less so. In effect, revitalization leads to more revitalization; reclamation leads to more reclamation. Kaurna can be made modern, un-relic itself, be made 'living'

\section{THE LANGUAGE-DEATH-METAPHOR}

It should be at least a bit clear by this point that I have very little by way of regard for the language-death-metaphor, or any variation on the theme. The reaching goes beyond the reach of the reacher, the metaphor stretched so thin the rips start to form and tear. Take your pick: revitalization framed as 'resuscitation' or even "language resurrection” (Amery 25), perceived choices made by speakers as "language suicide” or 'murder' (Crystal 86), dictionaries (presumably only for languages now 'extinct') described as "dodo birds in museums" (Harrison 7), or even crosslinguistic negotiation and exchange simplified to Darwin's "only the fittest will survive” (Batibo 85), a biological competition without a biology, and the losers, the "victim languages" (Krupnik 19) get 'murdered'.

But at the center of the deluge of personifications and wording lifted straight from a criminal (or legal) domain, is the language-death-metaphor. Language loss has been metaphorically represented as language 'death' since language loss became a subject for modern inquiry. But linguists often go further; they point not towards some figurative death, but a literal one: "to say that a language is dead is like saying that a person is dead. It could be no other way" (Crystal 1). This statement on its face is, of course, total nonsense, but it also points to the stringent belief that "languages have no existence without people" (Crystal 1). I would argue that that exact sentence will continue to exist (persist) as a form of English with or without people to read it, but I doubt it 
would find a receptive audience. For all intents and purposes, within the scholarship, a language is a living thing; it practically has a biochemistry.

The biochemical death of a speaker is not a process that shares any productive similarities with the kinds of language change we have been examining. The comparison is misleading, a language is not equivalent to its speakers. An obvious visible example of course is any kind of written text. That text is always in excess to the number of currently extant speakers. A language "simply [is] not an organism and to personify it as such is to misrepresent its nature" (Heller 248). The processes we have seen in the morphologies of languages as they are 'dying' show no serious difference to other kinds of change, yet through the death-metaphor becomes pathologized, as if the language had come down with an infectious disease. If this were true, they could be treated with some sort of scholarly medicine, but how do you recommend curing a vowel being fronted? How could that sentence even make sense?

Real death of an organism is an identifiable moment, yet "language death is a protracted change of state" (Mufwene 204). There is no moment that one can point to mark the end of a language. Many world languages exist for which there is no speaker. The broader scholarship says they are 'dead'. But the communities to whom these so-called 'dead' languages belong, like the Kaurna, see it "very differently. They see it as having been 'dormant' or 'sleeping' but nonetheless 'surviving'” (Amery 20). They emphasize "survival and continuity" (Amery 22). Even when the language-as-a-living-thing-metaphor persists, it does not require or presuppose a language-death-metaphor; it is a matter of emphasis.

So, if the language-death-metaphor does not accurately reflect the process of attrition, why does it persist in usage amongst linguists? It is a little hard to believe the phenomenon is accidental. Since at least the mid- $20^{\text {th }}$ century, much has been invested in a very specific model of languages, one that is fundamentally dependent on a separation between 'natural' languages and 'artificial' ones. This 'naturalness' could be the source of the living-organismmetaphor, and perhaps the language-death-metaphor too. What I mean is that to a specific, dominant group of linguists, language 'death' always "results in a discontinuity. Anything that might be attempted after that is artificial and not the same language" (Amery 22). To these kinds of thinkers then, a community reclaimed variant of Kaurna must have more in common with Esperanto than with the 'original' Kaurna. The 'natural' model requires that we equate a language to its speakers, which by now, I hope, is clearly at least partly problematic. The language does not have a biochemistry; linguists graft the biochemistry of the speakers onto the language. This model and its metaphors would be harmless enough, but they do not exist in a neutral vacuum. The language-death-metaphor serves "to devalue, marginalize or question the 
authenticity of language revival efforts” (Amery 23). The language-deathmetaphor effectively 'kills' efforts to prevent the 'death' of languages. The metaphor itself is 'killing' languages. And there are many, less linguistically violent options. 'Alive' instead could be something like changing or dynamic. 'Dead' in fact could be presented as something static and/but stable.

\section{PHASING}

Maybe 'dying' could instead be framed more like phasing. Instead of 'dying' many 'deaths', which never seem to result in 'death', only to reemerge as even more dynamic, as even more adaptable, as even more robust, before fading again from use and so on; perhaps languages possess a capacity for another type of change, that while distinctive from shift or creolization, is not particularly dire or remarkable. Languages change morphologically, they interact and exchange with other languages in the larger linguistic ecosystem, and they also change in terms of domains of usage, of ability to adapt and incorporate new domains in their scope, to generate new creative texts. I call this type of change phasing.

Linguistic phasing is the movement of a language on a dynamic spectrum of use, a gradient from absolutely dynamic and able to adapt to all new linguistic situations, to absolutely static, what was once called 'extinct', but is something more similar to frozen or paused. These static languages include the multitude of global ancient languages, buried somewhere amongst crumbly columns and sarcophaguses; and also includes the contemporary indigenous languages that are losing or have lost all speakers. To phase back in, that is to say, to become more dynamic, for any more or less static language, requires speakers, as speakers are necessary to (re)introduce the language into various domains. To phase out also requires speakers, speakers to use a changing or perhaps new set of linguistic tools, or speakers to stop speaking, as the language doesn't simply evaporate. The dynamic languages, on the other hand, give the illusion of stability via longevity, but the more dynamic the language, in fact, the less stable by definition.

\subsection{English}

I have shown several examples of 'dead' languages, of (more) static languages, but a clear example of their opposite, the unstable giants, these always changing mirages of consistency, is, of course, English. It "could have died in the Middle Ages but didn't," English could have died many times and did not, and, at least twice, English 'died' and was replaced by English (Hoenigswald 347). When faced with texts from Old English, which is, of course, an English, "first time 
readers....are often surprised to find that it looks so unlike what they would have expected...they often do not even recognize the language as a variety of English" (Smith and Kim 123). The various Englishes, whether old, middle, or modern (amongst a large, but quantifiable list of others) are effectively unintelligible for current speakers of English.

English fades from use, like 'endangered' or 'dying' languages, in certain domains under Norman rule, before reemerging in the thirteenth and fourteenth century more dynamic, more robust, used in more sociopolitical contexts (Smith and Kim). Huge shifts in the language have entirely transformed English in both spoken and written forms. During the Great Vowel Shift in the Middle English period, there was "a drastic but (more or less) systematic reordering of long vowels" (Smith and Kim 223). We have seen similar changes in the languages we earlier called 'dead' and 'dying'. And further, the proliferation of divergent and distinctive American Englishes closely follows the losses of other European languages on the continent, in other words, they emerge out of the 'deaths' of the local languages of (initially European) settlers (Mufwene).

English, following the same types of change as these other 'dead' and 'dying' languages, 'dies' multiples 'deaths' and never 'dies'. Unless English is somehow special, or 'immortal,' then all languages can (or do) undergo the same transformation(s), the same phasing in and out from usage, the same internal evolutions. In the old parlance, "a given language may become extinct, but the process of language death is eternal” (Krupnik 19). To put it in a way that makes more sense (to me): all languages undergo phasing over time, changing in capacity for further dynamic change and creative linguistic production in new domains.

\section{CONCLUSIONS}

So, if phasing is, as I have argued, simply another identifiable aspect of the language change process, rather than some sort of extinction type event, then any dormant language is in some way potentially active again. A language is thereby somehow in excess of a general count of its speakers; it 'outlives' them. In texts and other representational objects, sure, but also in the narratives, also in the morphology of other languages, also in the syntax of the prior proto language. The language sits somewhere in something, it is only a question of to what extent we still have access. If a language left absolutely no trace, then I would not even know that it once was once a language in the first place; any language of which I or you or anyone else can speak exists in some kind of space, no matter how miniaturized, invisible or withdrawn. 
The language-death-metaphor is not only a problem because it does not actually describe any process that necessarily indicates the (in)viability of a given language (or as separate from other forms of change). It is not only a problem because remaining (or former) speakers of so-called 'dead' languages absolutely do not consider their language dead or gone, and they will always know better, and know more completely, than anyone I have quoted, and especially more than me. It is not only a problem because many 'dead' languages, like Latin, carry on 'living' just fine regardless. It is not only a problem because the process is better described with clearer terminology (like phasing). A language does not die, because it doesn't live; its speakers do. A language does not die because it is larger than its set of speakers, and it takes on many other material forms. A language is more than its speakers, and less than any one of them.

Theory is ultimately a (set of) tool(s) we use to be able to talk about a given thing that we would otherwise struggle to articulate. That is it; that is all. Metaphor can likewise fulfil a similar, if not the same, function. We need to use some sort of tool. I am just saying that our choice of which tool, which term, the theory or the metaphor, matters. And if (when) we come to really get that, to realize that what we are saying is not saying what we are trying to say, then, maybe, we ought to say it differently.

\section{Works Cited}

Amano, Tatsuya, et al. "Global Distribution and Drivers of Language Extinction Risk." Proceedings of the Royal Society B: Biological Sciences, vol. 281, no. 1793, 2014.

Amery, Rob. Warraparna Kaurna! Reclaiming an Australian Language. University of Adelaide Press, 2016.

Bar-Asher, Moshe. "Some Observations on the Revival of Hebrew." Jewish Studies, vol. 32, 1992, pp. 25-42.

Batibo, Herman. "The Fate of Ethnic Languages in Tanzania.” Language Death: Factual and Theoretical Explorations with Special Reference to East Africa, edited by Matthias Brenzinger, Mouton De Gruyter, 1992, pp. 85-98.

Boltokova, Daria. “'Will the Real Semi-Speaker Please Stand up?' Language Vitality, Semi-Speakers, and Problems of Enumeration in the Canadian North." Anthropologica, vol. 59, no. 1, 2017, pp. 12-27.

Brenzinger, Matthias, and Gerrit J. Dimmendaal. "Social Contexts of Language Death.” Language Death: Factual and Theoretical Explorations with Special Reference to East Africa, edited by Matthias Brenzinger, Mouton De Gruyter, 1992, pp. 35.

Campbell, Lyle, and Martha C. Muntzel. "The Structural Consequences of Language Death.” Investigating Obsolescence: Studies in Language Contraction and 
Death, edited by Nancy C. Dorian, Cambridge University Press, 1989, pp. 181196.

Collins, James T. "Language Death in Maluku: the Impact of the VOC." Journal of the Humanities and Social Sciences of Southeast Asia, vol. 159, no. 2, 2003, pp. 247-289.

Counceller, April. “A Decade of Language Revitalization: Kodiak Alutiiq on the Brink of Revolution.” Journal of American Indian Education, vol. 51, pp. 15-29.

Crystal, David. Language Death. Cambridge University Press, 2017.

Dimmendaal, Gerrit J. 1989. “On Language Death in Eastern Africa.” Investigating Obsolescence: Studies in Language Contraction and Death, edited by Nancy C. Dorian, Cambridge University Press, 1989, pp. 13-31.

Dorian, Nancy C. “The Fate of Morphological Complexity in Language Death: Evidence from East Sutherland Gaelic.” Language, vol. 54, 1978, pp. 590-609.

Fernando, Chrisantha, et al. "A Model of the Mechanisms of Language Extinction and Revitalization Strategies to Save Endangered Languages.” Human Biology, vol. 82, no. 1, 2010, pp. 47-75.

Grimes, Joseph E. "Language Endangerment in the Pacific.” Oceanic Linguistics, vol. 34, 1995, pp. 1-12.

Harrison, David K. When Languages Die: The Extinction of the World's Languages and the Erosion of Human Knowledge. Oxford University Press, 2007.

Heller, John L. “Is Latin a Dead Language?” The Classical Journal, vol. 58, 1963, pp. 248-252.

Hill, Jane H. “Language Death in Uto-Aztecan.” International Journal of American Linguistics, vol. 49, 1983, pp. 258-276.

Hill, Jane H. "The Social Functions of Relativization in Obsolescent and Nonobsolescent Languages." Investigating Obsolescence: Studies in Language Contraction and Death, edited by Nancy C. Dorian, Cambridge University Press, 1989, pp. 149-164.

Hoenigswald, Henry M. "Language Obsolescence and Language History: Matters of Linearity, Leveling, Loss, and the Like.” Investigating Obsolescence: Studies in Language Contraction and Death, edited by Nancy C. Dorian, Cambridge University Press, 1989, pp. 347-354.

Karttunen, Frances, and Alfred W. Crosby. "Language Death, Language Genesis, and World History.” Journal of World History, vol. 6, 1995, pp. 157-174.

Krupnik, Igor. "Extinction of the Sirenikski Eskimo Language: 1895-1960." Etudies/Inuit/Studies, vol. 15, 1991, pp. 3-22.

McCarty, Teresa L. "Revitalising Indigenous Languages in Homogenising Times.” Comparative Education, vol. 39, 2003, pp. 147-163.

Mufwene, Salikoko S. "Language Birth and Death.” Annual Review of Anthropology, vol. 33, 2004, pp. 201-222.

Sasse, Hans-Jürgen. "Language Decay and Contact-Induced Change: Similarities and Differences." Language Death: Factual and Theoretical Explorations with Special Reference to East Africa, edited by Matthias Brenzinger, Mouton De Gruyter, 1992, pp. 49-80. 
Sasse, Hans-Jürgen. “Theory of Language Death.” Language Death: Factual and Theoretical Explorations with Special Reference to East Africa, edited by Matthias Brenzinger, Mouton De Gruyter, 1992, pp. 7-30.

Smith, Aaron K., and Susan M. Kim. This Language, A River: A History of English. Broadview Press, 2018.

UNESCO Ad Hoc Expert Group on Endangered Languages. Language Vitality and Endangerment. 2003.

Whalen, D. H., and Gary F. Simons. "Endangered Language Families.” Language, vol. 88, 2012, pp. 155-173.

Woolard, Kathryn A. "Language Convergence and Language Death as Social Processes.” Investigating Obsolescence: Studies in Language Contraction and Death, edited by Nancy C. Dorian, Cambridge University Press, 1989, pp. 355367.

\section{BIONOTE}

Jonathan Blake FOSTAR is a PhD candidate and instructor in the English department at Illinois State University. His website is dreamboybook.club.

Email: jbfosta@ilstu.edu 